\title{
Research on the Curriculum System of Social Sports Guidance and Management Major in Colleges
}

\author{
Yong Liu \\ Department of Physical Education, Yulin University, Yulin, 719000
}

Keywords: Curriculum System, Social Sports Guidance Management, College Education

\begin{abstract}
Economic development led to the development of sports, social sports more and more attention, enrollment institutions increased year by year, making the competitiveness of local institutions have been severely challenged. This paper clarifies the basic ideas of the curriculum construction of social sports guidance and management in local colleges and universities, and finds out the relationship between supply and demand in local sports market. It is proposed that the curriculum system of social sports guidance and management should be reconstructed from the aspect of curriculum system, the proportion adjustment of compulsory and elective courses and the determination of the main course, and the key construction should be carried out according to the regional characteristics.
\end{abstract}

\section{Introduction}

Social sports guidance and management is accompanied by the rapid development of society, people's living standards continue to improve, the development of national fitness activities arising from the professional. The professional training of personnel need to master the basic theoretical knowledge of social sports and basic skills to guide people to carry out sports fitness and recreation, mainly in the social sports activities. In recent years, Hebei Province, actively respond to the national fitness activities called for a variety of fitness competitions, fitness training, people are increasingly aware of the important role of physical activity on health. A variety of fitness and entertainment places unusually hot, people are willing to spend money to buy health. In theory, with the rapid participation of people in the community to participate in sports activities, the rapid development of sports market, the community will need a lot of sports managers, social sports instructors, sports health workers and so on. In this social context, social sports guidance and management students should usher in a good opportunity. But the professional graduates of the employment situation and did not imagine so optimistic, why the emergence of such a society requires a lot of sports talent, and graduates looking for work is still difficult situation? First, the community on the large number of sports talent demand is a potential phenomenon, the reality is now the situation is oversupply; Second, students choose the concept of different career, graduates choose to the senior club or Relatively stable school employment; third, the ability of graduates can not meet the requirements of the employer; Fourth, the current social sports guidance and management professional is still in its infancy, colleges and universities in the professional curriculum problems, so that students graduate In the state is not low is not low. To solve the problem of supply and demand contradiction requires a lot of efforts, including colleges and universities play a pivotal role. In the hard work of colleges and universities, it is very important to adjust the training objectives of social sports guidance and management specialty and improve the curriculum of this specialty. Education plays a leading role in the process of human development, especially in school education, giving a more comprehensive, systematic and profound experience in school. The education is done through the teaching of the teacher. The knowledge is disseminated in the form of the curriculum. To achieve. So how to set up courses for college education is essential. Curriculum is to achieve the goal of cultivating the necessary conditions, affecting the quality of personnel training. Social sports guidance and management graduates need to have a good moral level, master the rich professional knowledge and ability, it is possible in people's lives 
to play its due role, to achieve their own value for the benefit of society, and in these Need to achieve the level of competence in the training objectives and curriculum set to dominate.

\section{The Current Situation of Curriculum Design for Social Sports Guidance and Management in Some Universities in China}

Curriculum design is the concrete embodiment of the goal of personnel training, curriculum should be a comprehensive consideration of social, disciplines, students need to develop personality. By analyzing the social sports guidance and management professional training program of 18 colleges and universities, it is known that the curriculum of each university is different.

6 colleges and universities social sports guidance and management of the general provisions of the total of 2644 hours of school, in line with the Ministry of Education on social sports undergraduate courses in the total hours of $2600 \sim 2800$ hours of the provisions of compulsory courses, including compulsory and compulsory courses 2 (1 080 hours); elective courses include restricted elective courses and optional courses, 6 colleges and universities compulsory courses average total hours of study For the 836 hours, with the Ministry of Education required compulsory courses (900 hours) basically consistent. If you only learn from the professional course, compulsory course, elective class 3 parts to see, basically meet the requirements of the Ministry of Education, but from the specific set of curriculum analysis, there are still problems.

At present, the curriculum of social sports guidance and management in our country mainly has the following problems: (1) lack of professional characteristics of curriculum; (2) lack of relatively fixed professional basic courses and core courses; (3) the proportion of courses less reasonable. More theoretical hours, less practical practice.

Training specifications to cultivate the goal-oriented, is the overall requirements of social sports professionals, including quality requirements and capacity requirements of the two major aspects. With the social demand for social sports professionals continue to change the requirements of the colleges and universities are based on the provisions of the Ministry of Education, combined with the actual situation of the school training specifications were modified and added. Through the access to training programs found that, in addition to the different requirements in terms of business quality, the school requirements are generally similar. Such as Handan College requires the professional students familiar with the sports fitness industry and youth sports training market development status to the heart service, with sports fitness training ability, sports fitness knowledge promotion ability, sports fitness business management ability. Yanshan University requires the graduates to master the skills and guidance skills to guide the fitness and leisure sports; have engaged in mass sports activities planning, consulting, development and organization and management of the basic ability and can engage in teaching work. "Professional norms" in the provisions of training objectives and training in accordance with the basic requirements of the premise, to allow the school according to the actual situation. In the professional direction, teaching content, knowledge system, curriculum and practice teaching links to reflect the professional characteristics.

The skill transfer and physical activity characteristics of the sports profession determine that the achievement of the professional training goal must be ensured by a quantitative and well-qualified sports venues. Through the survey found that the current social sports guidance and management of Hebei Province, the basic facilities to meet the needs of teaching, most of the technical and physical education and the Department of public education teaching sites. There are fewer places in public schools in the same district. But some of the social sports guidance and management expertise unique, costly venues shortage, such as swimming pool, golf course, training and training field. In the face of this problem, schools can invest in the construction of venues, but also to strengthen the inter-school cooperation and common venues, as well as leasing clubs, sports companies and other business venues set to ensure the successful completion of teaching. 


\section{Construction of Social Sports Curriculum System}

Establish and improve the ability of the application of qualified personnel training new program. According to the school's orientation and application of personnel training objectives, the school will be able to apply the concept of capacity-based professional personnel training to social needs as the guide to determine the objectives and specifications of personnel training, to build a capacity-based training to professional competence as the core of the application of personnel training program, after several years a total of five revisions to the 2014 version of the school social sports guidance and management professional application of personnel training program tends to mature and stereotypes, and has its own more prominent features. Training objectives. The professional training of social sports guidance and management of the basic theory, basic knowledge and basic skills, with fitness training, mass sports activities planning and organization and sports industry management and management capabilities, capable of social sports work Talent. Training specifications. The requirements of public capacity: with the correct political direction and scientific world outlook, outlook on life and values, with the correct concept of the rule of law, good moral character and professional ethics; with English listening, speaking, reading, writing, translation of the basic Ability, through the level of college English application proficiency test; master the basic knowledge of computer culture and basic skills, through the non-computer professional students computer level examination; with a healthy physique, tenacious will quality and good psychological quality, develop good labor Habits, to master a certain degree of labor skills, at least through the two professional qualification. Professional ability requirements: with the use of basic knowledge of sports, basic skills; have the ability to guide sports fitness; with national, folk traditional sports guidance; with social sports survey and scientific research capabilities. Development capacity requirements: a special sports with the ability to guide; with social sports work organization and management capacity; with social sports industry development and management capacity; with sports health and rehabilitation capacity. Core course. Introduction to Social Sports, Sports Club Management, Introduction to Sports Management, Introduction to Community Sports, Sports Economics, Health Evaluation and Sports Prescription, Sports Project Theory and Practice. School system and degree. Duration: four years. Degree: Bachelor of Education. Hours and credits: class hours / class points for the 2 433/150.

Increase the practice of teaching hours. Practice teaching hours accounted for the proportion of the total hours from the original $46 \%$, increased to the current $55.13 \%$, social sports guidance and management professionals are practical strong application of professional, increase the practice of teaching hours and credits, and social needs, It is the only way to adapt the development of the situation and to reform the teaching mode by introducing the teaching practice into the teaching process.

Add capacity to develop activities. According to the professional training requirements, the establishment of the social sports instructors, referees level training, sports quality standards and other competencies to expand the activities of the curriculum, and actively carry out various sports social sports instructors, referees training grading work, the implementation of student quality training each year, Require students to graduate, at least get a project of two social sports instructor card and the national two referee certificate, so that the professional ability of students to be further enhanced.

The Effect of Curriculum System Reform. (1) the student's athletic competition ability is significantly improved. To participate in the 2014 Provincial College Games by the college group of the total score of the first; cheerleading team to participate in the 2016 national student cheerleading championships, the physical education group group total score first, collective self-selected skills group 1 Name, double dance skills first. After the game, by the Hunan Satellite TV "Happy Camp" program group's invitation, cheerleader and table tennis Olympic champion Zhang Jike and other stars participated in the "five ring theme" program recording, broadcast in Hunan Satellite TV: dance team 2015 In October 2016, in the national "dancing in China - row dance finals", won the small group skewed ordinary institutions group first in the group, One, the national original row 
dance ordinary college group first, open group 2, our school by the State Sports General Administration Gymnastics Sports Management Center, the national dance sports promotion center jointly issued the "four-star model school" title. (2) the organization of students, the ability to significantly improve the referee. In recent years, students have undertaken the organization and referee work of Huaihua City's large-scale sports track and field, basketball, table tennis, badminton, soccer, martial arts, aerobics, cheerleading, ethnic minority games. 2013, 2014 National Table Tennis Club A, A B League referee work. (3) the ability of students to serve the community to further strengthen. In 2014, under the leadership of teachers, 20 students participated in the physical monitoring of the people of Huaihua City, and wrote a monitoring report to provide an important basis for improving the physical health of Huaihua citizens. (4) the employment rate of graduate students increased. 2015, 2016 social sports guidance and management of graduates of the average initial employment rate of $90 \%$ or more.

\section{Conclusion}

According to the application of personnel training objectives, the ability-based concept applied to the development of professional personnel, to develop capacity-based training, professional ability training as the core of the application of personnel training program is the social development of social sports guidance and management professional training The need. The construction of curriculum system of public ability training curriculum module, professional ability training course module and development ability training curriculum module not only embodies the professional characteristics, but also combined with social employment needs, which embodies the professional training objectives and specifications. Based on the establishment of the core curriculum, the application of the training program should establish a dynamic adjustment mechanism of the curriculum, so that the curriculum system can be more closely combined with the market demand and professional requirements, and more reflect the requirements of the ability to cultivate the standard.

\section{Acknowledgements}

Yulin college professional talent training scheme reform research project in 2017(TJG1752)

\section{References}

[1] Zhang Guiting, Lv Feng, Yan Dangyan, Wang Zhili.Study on the Reform of Graduation Practice Teaching in the Guidance and Management of Social Sports in Colleges and Universities - Taking Xingtai College as an Example [J]. Journal of Xingtai University, 2017 (03)

[2] Fan Ying. Social sports guidance and management of professional practice reform [J]. Contemporary Sports Science and Technology. 2015 (30)

[3] Liu Xuepeng. Social sports guidance and management of professional practice optimization [J]. Sports World.) 2016 (10)

[4] Zhang Haixin, Wang Shuying. Shijiazhuang City social sports guidance station development status quo analysis [J]. Industry and Technology Forum. 2017 (14)

[5] Chizhou. University provincial "social sports guidance and management (sports tourism)" professional comprehensive reform pilot project [J].Journal of Chizhou University (2015)

[6] Du Dayong. Social sports guidance and management of professional practice teaching system construction and analysis [J]. Contemporary sports science and technology. 2016 (14) 